\title{
Defect Detection in Pipelines during Operation Using Magnetic Flux Leakage and Phased Array Ultrasonic Method
}

\author{
Radoslav Konar ${ }^{1}$, Milos Mician ${ }^{1}$, Ivo Hlavaty ${ }^{2}$ \\ ${ }^{1}$ Department of Technological Engineering, Faculty of Mechanical Engineering, University of Zilina in Zilina. Univer- \\ zitna 1, 01026 Zilina. Slovak Republic. E-mail: radoslav.konar@fstroj.uniza.sk, milos.mician@fstroj.uniza.sk \\ ${ }^{2}$ Faculty of Mechanical Engineering, VSB - Technical University of Ostrava, 17. listopadu 15, 70833 Ostrava. Czech \\ Republic. E-mail: ivo.hlavaty@vsb.cz
}

The present article is focused on the non-destructive testing (NDT) inspection of pipelines during operation namely Magnetic Flux Leakage (MFL) method and Phased Array ultrasonic (PA) method. MFL inspection technique is electromagnetic test method primarily used to detect flaws or defects in high-permeability of ferromagnetic metals such as carbon steel tubing, plate, wire rope and tubular parts. PA ultrasonic method is an advanced NDT method that is used to detect component failures i.e. cracks or flaws and thereby determine component quality. Due to the possibility to control parameters such as beam angle and focal distance, this method is very efficient regarding to the defect detection and speed of testing. In this article real pipeline defect was identified by MFL method in the internal pipe inspection. This defect was fully mapped by Phased Array ultrasonic method in the terrain. 3D model of defect in the tested material was created from measured data and obtained by PA method. The real dimensions of the defect determined from measurements by the method of MFL and PA are compared.

Keywords: Non-destructive Testing, Magnetic Flux Leakage, Phased Array, Gas Pipeline Inspection

\section{Acknowledgement}

This work has been supported by non-profit organization EkoFond project No. 561/PG04/2011.

\section{References}

[1] PARK, S. (2014). Magnetic Flux Leakage Sensing-Based Steel Cable NDE Technique. In: Shock and VibrationAdvanced in Structural Health Management and Composite Structures 2012, pp. 1-8, Hindawi Publishing Corporation, London

[2] KUMAR, M., SORABH (2013). Inspection of Pipelines Using MFL Technique. In: Confab Jourmal, pp. 13-17. Confab Journal, India

[3] LANGENBERG, K., J., MARKLEIN, R., MAYER, K. (2012). Ultrasonic nondestructive testing of materials Theoretical foundations. pp. 772. CRC Press, New York.

[4] ANDROSOVA, Z., SKRBEK, B. (2012). The use of magnetic and ultrasonic structuroscopy for inspection of ADI/AGI castings. In: Manufacturing technology, pp. 93-97. J.E. Purkyne University, Ústi nad Labem.

[5] NOVAK, P., MESKO, J., ZMINDAK, M. (2011). Finite element implementation of multi-pass fillet weld with phase changes. In: Manufacturing technology, pp. 79-85. J.E. Purkyne University, Ústi nad Labem.

[6] KONAR, R., MICIAN, M. (2012). Numerical simulation of residual stresses and distortions in butt weld in simulation programme SYSWELD. In: Communications, pp. 49-54. EDIS, Žilina.

[7] ZMINDAK, M. et al. (2014) Fiite element analysis of crack growth in pipelines. In: Manufacturing technology, pp. 116-122. J.E. Purkyne University, Ústi nad Labem.

[8] MICIAN, M., PATEK, M., SLADEK, A. (2014). Concept of Reapiring Branch Pipes on High-pressure Pipelines by Using split Sleeve. In: Manufacturing technology, pp. 60-66. J.E. Purkyne University, Ústi nad Labem.

[9] DOPJERA, D., MICIAN, M. (2014). The Detection of Artificially Made Defects in Welded Joint with Ultrasonic defectoscopy Phased Array. In: Manufacturing technology, pp. 12-17. J.E. Purkyne University, Ústi nad Labem.

[10] OLYMPUS (2013). The company Olympus NDT. Online: <http://www.olympus-ims.com/cs>. 